\title{
Variability in tropospheric carbon monoxide over an urban site in Southeast Asia
}

\author{
L.K. Sahu ${ }^{\mathrm{a}, *}$, Varun Sheel ${ }^{\mathrm{a}}$, M. Kajino ${ }^{\text {b,c }}$, P. Nedelec $^{\mathrm{d}}$ \\ a Physical Research Laboratory (PRL), Navrangpura, Ahmedabad, Gujarat 380009, India \\ ${ }^{\mathrm{b}}$ Meteorological Research Institute, Japan Meteorological Agency, Tsukuba, Japan \\ ${ }^{c}$ Pacific Northwest National Laboratory, Richland, WA, USA \\ d Laboratoire d'Aérologie, CNRS, Observatoire Midi-Pyrénées, UMR 5560, 14 Avenue Edouard Belin, 31400 Toulouse, France
}

This paper analyses MOZAIC (Measurements of Ozone aboard Airbus in-service airCraft) measurements of carbon monoxide ( $\mathrm{CO}$ ) profiles over Bangkok to discuss the seasonality in vertical distribution during year 2005-2006. The mixing ratios of CO were enhanced in the lower troposphere being highest in winter followed by summer and wet seasons. During all the seasons, the mixing ratio of CO decreased rapidly and remained low in the middle troposphere. At higher altitudes $(6-12 \mathrm{~km})$, CO shows enhanced values particularly during wet and early winter seasons. The strong seasonality in $\mathrm{CO}$ was caused by the seasonal shift in the patterns of the long-range transport and biomass burning (BB) in South and Southeast Asia (S-SE Asia). Flow of cleaner air and negligible BB resulted in the lowest mixing ratio of $\mathrm{CO}$ in the wet season. In addition to anthropogenic influence, the long-range transport and $\mathrm{BB}$ caused the higher $\mathrm{CO}$ in the winter and summer seasons, respectively. Despite extensive local BB activities in Thailand during the summer season, the moderate levels of $\mathrm{CO}$ were attributed to the dilution due to flow of cleaner marine from the Indian and Pacific Oceans. We have also compared the observations with the Model for Ozone And Related Chemical Tracers (MOZART) simulations. Mostly the observations lie between the MOZART-2 and MOZART-4 simulations as they underestimate and overestimate the observed $\mathrm{CO}$, respectively. In the middle and upper troposphere, both the observed and simulated mixing ratios of CO during September-November of year 2006 were higher by 15-30 ppbv compared to the same period of year 2005. Our analysis indicates the impact of El Niño induced extensive BB in Indonesia during the year 2006.

\section{Introduction}

Carbon monoxide ( $\mathrm{CO}$ ) is mainly emitted from incomplete combustion of fossil fuel (FF) and biomass burning (BB), while oxidation of methane $\left(\mathrm{CH}_{4}\right)$ and volatile organic compounds (VOCs) can significantly contribute to the atmospheric budget of CO (Jaffe et al., 1997; Holloway et al., 2000). These sources also emit other gaseous and particulate species which play important roles in the chemistry and climate of the earth's atmosphere

* Corresponding author. Tel.: +91 (0)79 2631 4553; fax: +91 (0)79 26314900. E-mail addresses: lokesh@prl.res.in, 1_okesh@yahoo.com (L.K. Sahu).
(Duncan et al., 2003; Streets et al., 2003a, b). Typically, the emissions of CO from vehicular traffic and industrial activity are year-round and do not show significant seasonality. On the other hand, emissions of $\mathrm{CO}$ from BB-related sources such as forest fire, savanna fire, and agricultural waste burning exhibit strong seasonality (Jaffe et al., 1997). In terms of causes, locations, and timing the emissions of $\mathrm{CO}$ from BB sources are different from anthropogenic or FF-related sources.

Reaction with the hydroxyl $(\mathrm{OH})$ radical is the primary sink of $\mathrm{CO}$ in the atmosphere. In the troposphere, the reaction between $\mathrm{CO}$ and $\mathrm{OH}$ represents $90-95 \%$ of the CO sink, and about $75 \%$ removal of OH (Novelli et al., 1998; references therein). In the downwind of 
polluted urban or open BB sources, the photochemistry of CO can lead to the net production of $\mathrm{O}_{3}$ (Fishman and Seiler, 1983). The transport of $\mathrm{CO}$ emitted from different sources and regions in Asia has been observed to impact the remote regions of troposphere (Lelieveld et al., 2001; Cooper et al., 2004; Sahu et al., 2006). The mixing ratio of $\mathrm{CO}$ has been used as a tracer for the long-range transport due to reasonably long photochemical lifetime of 1-2 months in tropical troposphere (e.g., Jaffe et al., 1997; Allen et al., 1999; Shindell et al., 2006). CO is a pollutant and exposure to high levels can impact the human health (Maynard and Waller, 1999; Sahu and Lal, 2006).

Anthropogenic emissions of $\mathrm{CO}$ and various other pollutants in Asia are increasing due to rapid industrialization and urban development (Streets et al., 2003a; Ohara et al., 2007). The regional inventories of $\mathrm{CO}$ and various other gaseous pollutants over Asia have been reported in the literature (Olivier et al., 2002; Streets et al., 2003a; Heald et al., 2003). van der Werf et al. (2006) have reported that the global emissions of $\mathrm{CO}$ from $\mathrm{BB}$ sources could be about 15\% higher compared to those emitted from FF sources. The Asian emissions of CO were estimated to be $\sim 279 \mathrm{Tg}$ in the year 2000 of which almost 50\% originated from the BB sources, especially from slash-and-burn agriculture and deforestation (Streets et al., 2003b). Emissions of CO in S-SE Asia from BB sources exhibit strong seasonality with a primary peak during FebruaryApril and secondary peak during August-October (Streets et al., 2003b). In SE Asia, including Indonesia and Malaysia, emissions

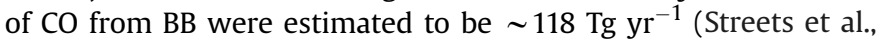
2003b).

The spatial and temporal variations of CO have been characterized based on the measurements using different techniques such as remote sensing from the space, ground based remote sensing, and in-situ sampling. Emmons et al. (2000) have compiled the global tropospheric data of $\mathrm{CO}$ obtained from a number of aircraft campaigns during 1983-1999. However, the aircraft observations in Asia are negligibly small compared to those in North America and Europe. Most of the studies of CO in Asia have relied on data from space borne techniques such as the Measurement of Air Pollution from Space (MAPS) (web page http://www.nasa.gov/centers/ langley/news/factsheets/MAPS.html), Scanning Imaging Absorption Spectro Meter for Atmospheric ChartographY (SCIAMACHY) (http://www.sciamachy.org/), Atmospheric Infrared Sounder (AIRS) (http://www-airs.jpl.nasa.gov/), Tropospheric Emission Spectrometer (TES) (http://tes.jpl.nasa.gov/), Measurements Of Pollution In The Troposphere (MOPITT) (http://www.atmosp.physics.utoronto. ca/MOPITT/home.html).

The environmental and climatic impacts of BB in SE Asia have been well recognized based on the observational studies (Thompson et al., 2001). The present manuscript is based on the analysis of tropospheric profiles of $\mathrm{CO}$ measured over Bangkok using the MOZAIC data during 2005-2006. The objective of this study is to investigate the causes of variability in tropospheric $\mathrm{CO}$ using the meteorological, fire count, and back trajectory data. We have also presented a brief comparison of $\mathrm{CO}$ from the MOZAIC and simulations by MOZART. A comparison between model and observations will be an opportunity to evaluate the simulations in the tropical region.

\section{MOZAIC program and MOZART model}

The MOZAIC program was started in 1993 by the European scientists, aircraft manufacturers, and airlines supported by the European Union (EU) (Marenco et al., 1998). The MOZAIC flights are sponsored by Air France, Austrian Airlines, Lufthansa, and Sabena/ Air France. This project has been operational since August 1994 for the automatic measurements on board Airbus A340's on scheduled flights. In the second phase (1997-2000), the measurements of $\mathrm{O}_{3}$ and $\mathrm{H}_{2} \mathrm{O}$ were continued while instrumentations for $\mathrm{CO}$ and nitrogen oxides $\left(\mathrm{NO}_{y}\right)$ were developed for on board measurements. In the third phase (2001-2004), the aircrafts were equipped for automated in-situ measurements of $\mathrm{CO}$.

An improved version of Thermo Environmental Instruments (Model 48CTL) based on the Gas Filter Correlation (GFC) technique was used for the measurements of $\mathrm{CO}$. The absorption of IR radiation at a wavelength of 4.67 micron was used for the detection of CO. The measurement precision of \pm 5 ppbv (signal noise), $\pm 5 \%$ (calibration) and minimum detection limit of 10 ppbv were achieved for a $30 \mathrm{~s}$ integration time. Detailed description of measurement technique, instrument validation and quality testing were reported in Nedelec et al. (2003).

The flight observations taken during both take-off and landing of the aircraft provide the vertical profile data over the airports. In this study, we have used about 143 profiles of $\mathrm{CO}$ measured over Bangkok during year 2005-2006. The histogram of the number of MOZAIC profiles in different months is shown in Fig. 1.

MOZART is a 3-D global chemical transport model of atmospheric composition designed to simulate both chemical and transport processes in the troposphere. MOZART-2 deals with 63 different chemical constituents employing 133 gas phase, 2 heterophase, and 33 photolytic reactions (Horowitz et al., 2003; Sheel et al., 2010). The horizontal resolution used in this run is $2.8 \times 2.8$ (equivalent to T42) translating to 128 longitude and 64 latitude grid points. Model can provide the simulations at 28 vertical sigma levels from surface to $\sim 40 \mathrm{~km}$ of altitude. The emission data of most species were taken from the Precursors of Ozone and their Effect on the Troposphere (POET). The POET inventory is based on the European projects of the Global Emission Inventory Activity (GEIA) and the Emissions Database for Global Atmospheric Research (EDGAR) (Olivier et al., 2003; 2005). The POET inventory gridded for $1 \times 1$ includes anthropogenic, fire, and natural emission data. The fire and natural emissions are monthly data, while anthropogenic emissions are annual. Anthropogenic emissions of $\mathrm{CO}$ and $\mathrm{NO}_{x}$ were replaced by the emission inventory for Asia (Regional Emission inventory in ASia (REAS) version 1.1) available at $0.5 \times 0.5$ grid. In this study, the meteorological fields taken from the National Centers for Environmental Prediction (NCEP) reanalysis is used for the MOZART simulations (Sheel et al., 2010). In our institute (Physical Research Laboratory), we run the model on the 3 Terraflop HPC Linux cluster with 20 nodes. A typical one year run takes about $12 \mathrm{~h}$ of time.

The modifications of MOZART-4 over MOZART-2 include detailed anthropogenic hydrocarbon chemistry, improved scheme

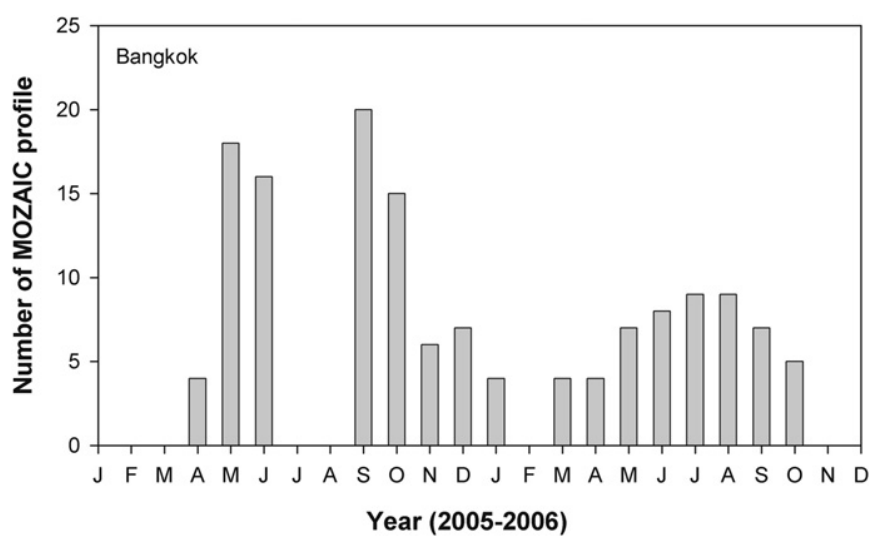

Fig. 1. The monthly histogram of number of MOZAIC profiles measured over Bangkok during year 2005 and 2006 
for determination of albedo, inclusion of tropospheric aerosols and online calculations of photolysis rates, dry deposition, $\mathrm{H}_{2} \mathrm{O}$ concentration and biogenic emissions (Horowitz et al., 2003). MOZART-4 simulates comprehensive tropospheric chemistry with 85 gas phase species, 12 bulk aerosol species, 39 photolysis and 157 gas phase reactions (Emmons et al., 2010). The model simulated at a resolution of $2.8 \times 2.8$ with 28 sigma pressure levels from the surface to $\sim 2 \mathrm{mb}$ using the NCEP's Global Forecast System (GFS) meteorological fields have been used in the present work. The emission inventories for major anthropogenic sources, i.e. FF combustion and biofuel burning used in the present simulations are taken from the POET for year 2000 (Granier et al., 2004). These anthropogenic emissions have been updated over Asia for year 2006 using REAS inventory developed by Ohara et al. (2007). The monthly averaged BB emissions for the given year of simulation are taken from the Global Fire Emission Database, version 2 (GFED-v2) (van der Werf et al., 2006).

\section{Site and emission sources in Bangkok}

Bangkok city is located in the southwest (SW) region of Thailand on the eastern bank of the Chao Phraya river near the Gulf of Thailand. Bangkok is the largest city in Thailand and one of the economically leading cities in SE Asia. The city is heavily populated with about $15 \%$ of the entire population of Thailand lives or works there. The population of greater Bangkok is about 10 million but the number of people officially registered is about 6 million. Bangkok and five surrounding provinces namely Samut Prakarn, Nonthaburi, Pathumthani, Nakorn Pathom, and Samut Sakorn are known as the Bangkok Metropolitan Region (BMR). The international airport (Suvarnabhumi, $13.72 \mathrm{~N}, 100.48 \mathrm{E}$ ) is located at about $33 \mathrm{~km}$ southeast (SE) from the main city center (see Fig. 2). According to the estimates there are more than 5.4 million vehicles running in the roads of Bangkok city (DLT, 2008). Vehicular traffic is a major source of air pollution in Bangkok. While other emission sources such as the Don Muang airport and small industrial estates are located at 30-40 km northwest (NW) from the Suvarnabhumi airport. The traffic in Bangkok consists of motorcycle (gasoline, 40\% of total), three-wheeler or "tuktuk" (liquefied petroleum gas (LPG), $0.2 \%$ ), car (gasoline/LPG/compressed natural gas (CNG), 37\%), taxi (LPG/CNG/gasoline, 1.6\%), van/pickup (diesel/CNG, 18\%), bus (diesel/ CNG, 0.6\%), and truck (diesel/CNG, 1.8\%) (DLT, 2010). Despite the increasing trend in total number of vehicles, the roadside measurements of $\mathrm{CO}$ in Bangkok show a steady reduction from 1992 to 2005 (BMA, 2009). The emissions from biomass burning and agricultural waste burning in the surrounding regions of Bangkok are also important source of various gaseous and particulate pollutants (Chuersuwan et al., 2008). Over $90 \%$ of rice straw is burned during the months of November to April, but the activities are particularly extensive during February-March (Tipayarom and Kim Oanh, 2007). Among the SE Asian countries, Thailand has the highest number of registered vehicles, while the amount of fuel and biomass burned was estimated to be second after Indonesia (Streets et al., 2003a, b).

\section{Seasonality in general circulation and meteorological parameters}

The three main seasons are wet (May-October), winter (November-February) and local summer (March-April) in Thailand (Pochanart et al., 2003; Sahu et al., 2011). The period from winter to summer is also known as the dry season. In most of Asia, the seasonal shift in the large-range transport is controlled by the progression of the Inter-Tropical Convergence Zone (ITCZ) (Asnani, 1993). The ITCZ is a region of lower pressure where winds from the northern and southern hemispheres come together. The wet season prevails due to the SW wind flow from the Indian Ocean and the winter season due to the northeast (NE) and northwest (NW) winds from the continents. The wet season is associated with the northward progression of the ITCZ which brings cleaner oceanic air from the southern Indian Ocean. In the winter season, the long-range transport of continental air mass mainly from the East Asia takes place due to the southward progression of the ITCZ. The observation site is influenced by the mixed air masses (marine and continental) during the summer season as the city is located near the Gulf of Thailand. In addition to the seasonal reversal in the ITCZ, the large scale phenomena like El Niño have been known to impact SE Asia. The coupled phenomena of El Niño and Southern Oscillation (ENSO) originate from cyclic warming and cooling of the surface oceans of the central and eastern Pacific. Several countries in SE Asia have been affected by the ENSO having the most severe impact in Indonesia.

The box-whisker plots in Fig. 3 show the monthly variations of surface level wind speed, RH, surface pressure, temperature, and total rainfall from January 2005 to December 2006. We have used the meteorological data recorded at Don Muang Airport (DMK) in Bangkok (http://www.wunderground.com). Based on the daily data, the monthly mean temperature varies between a minimum of $27{ }^{\circ} \mathrm{C}$ in the month of December and maximum of $32{ }^{\circ} \mathrm{C}$ in the month of March. The temperature tends to increase from March to
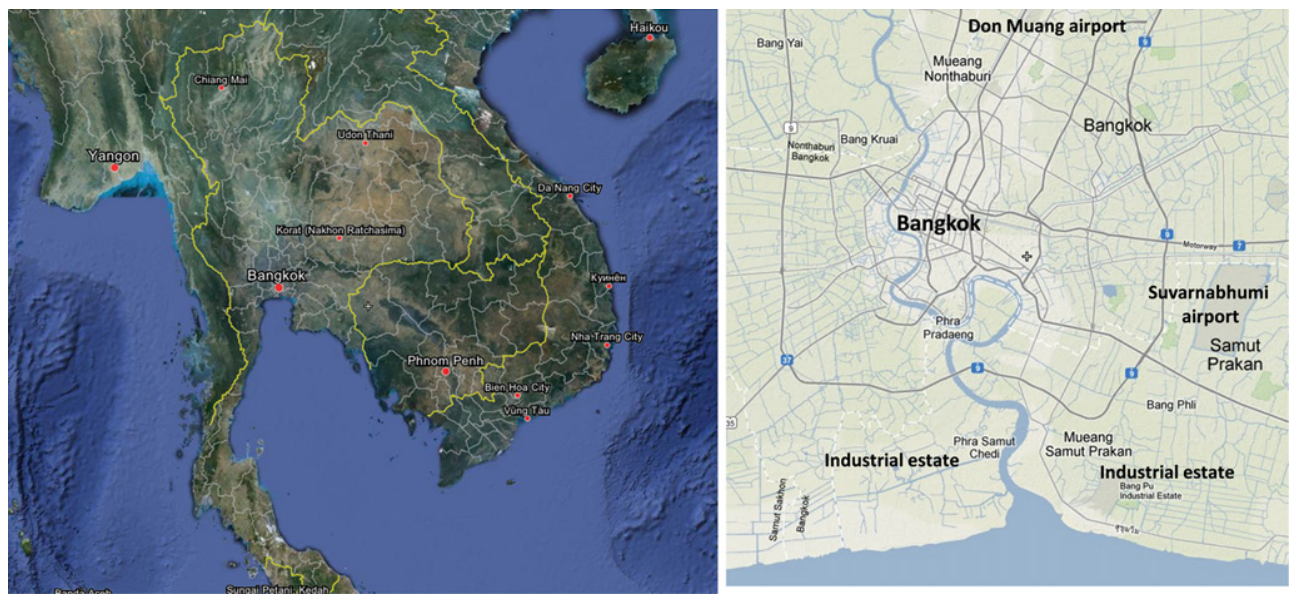

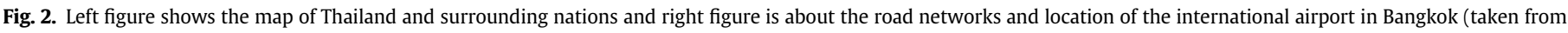
wikimapia web, http://wikimapia.org). 

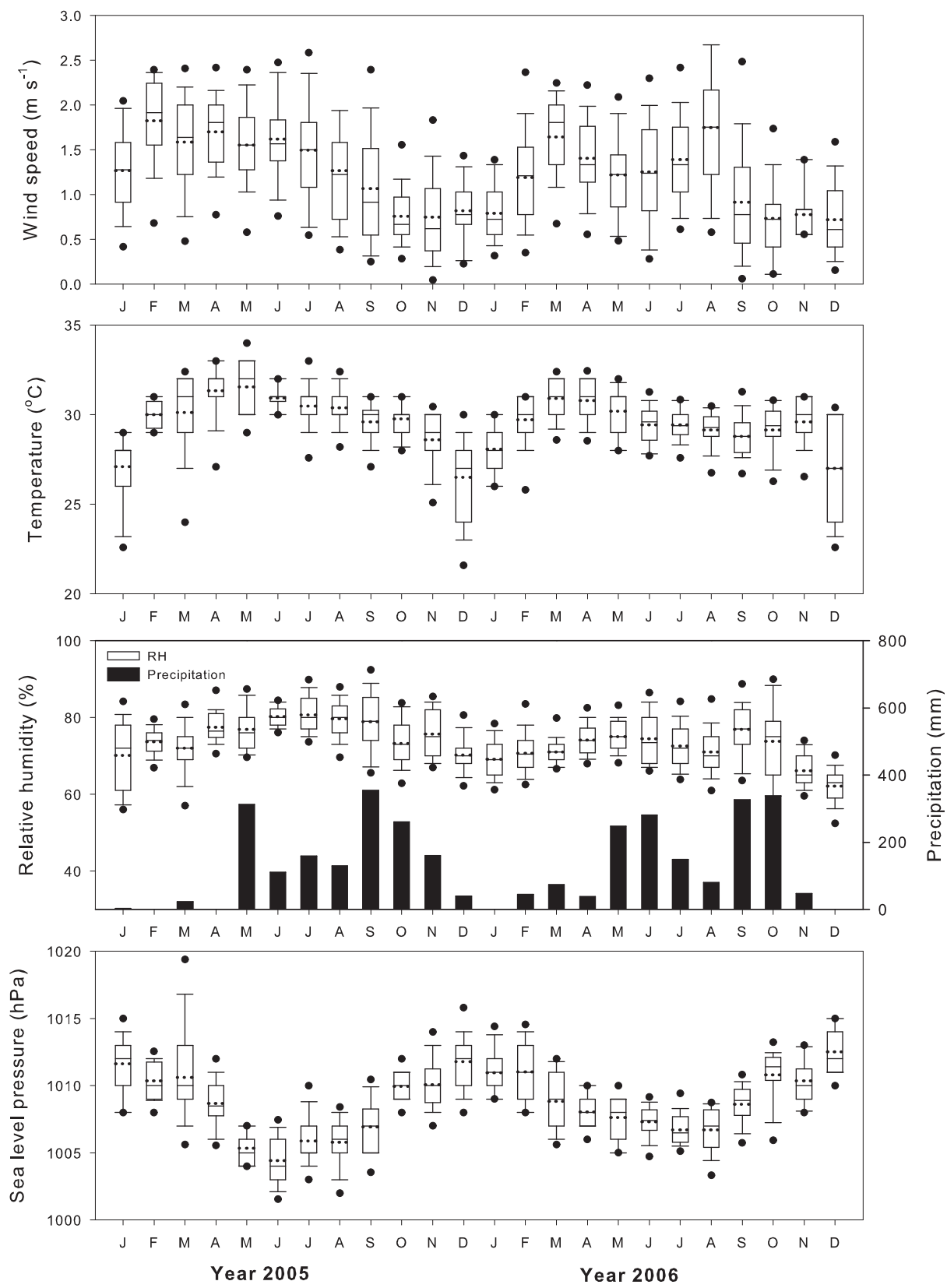

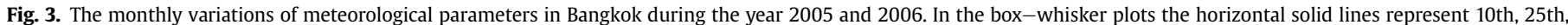
50th, 75th, and 90th percentiles, filled circles are 5/95th percentiles, and dashed lines give the mean obtained using daily data.

April (or till mid-May) therefore; this period is known as the summer season. The daily wind speed data shows large variability in Bangkok. During both the years, the monthly wind speed data shows slightly higher range $\left(1.0-2.0 \mathrm{~m} \mathrm{~s}^{-1}\right)$ in the wet season, while calm weather $\left(<1.0 \mathrm{~m} \mathrm{~s}^{-1}\right)$ prevailed during the winter months. The monthly median of sea level pressure varies in the ranges of 1004-1012 hPa and 1006-1012 hPa during the year 2005 and 2006, respectively with the lowest during June and highest in the month of December. The monthly RH varied in the ranges of $70-81 \%$ and $62-79 \%$ during the 2005 and 2006 , respectively. It is worth to mention that the levels of RH during October-December of 2006 were $\sim 10 \%$ lower compared to the values during same period of 2005. During both the years, the rainfalls during November to April were lowest and accounted for about less than $20 \%$ of annual rainfall therefore, this period is also known as the dry season. The annual rainfalls were $1685 \mathrm{~mm}$ and $1623 \mathrm{~mm}$ at Bangkok during the 2005 and 2006, respectively.

\section{Results}

\subsection{Vertical profiles of $\mathrm{CO}$}

The MOZAIC profiles of CO over Bangkok for the three different seasons are shown in Fig. 4. In detail, we have plotted all the data points (150 $\mathrm{m}$ height interval) along with their average, 5th percentile, and 95th percentile for each season. In wet season, the average mixing ratio of $\mathrm{CO}$ decreases from $\sim 250$ ppbv near the surface to $100 \mathrm{ppbv}$ at $2 \mathrm{~km}$ of altitude. In the middle troposphere (2-6 km), the mixing ratio of $\mathrm{CO}$ was lowest with a nearly constant value of about $85 \mathrm{ppbv}$. In the upper troposphere $(6-12 \mathrm{~km})$, the 

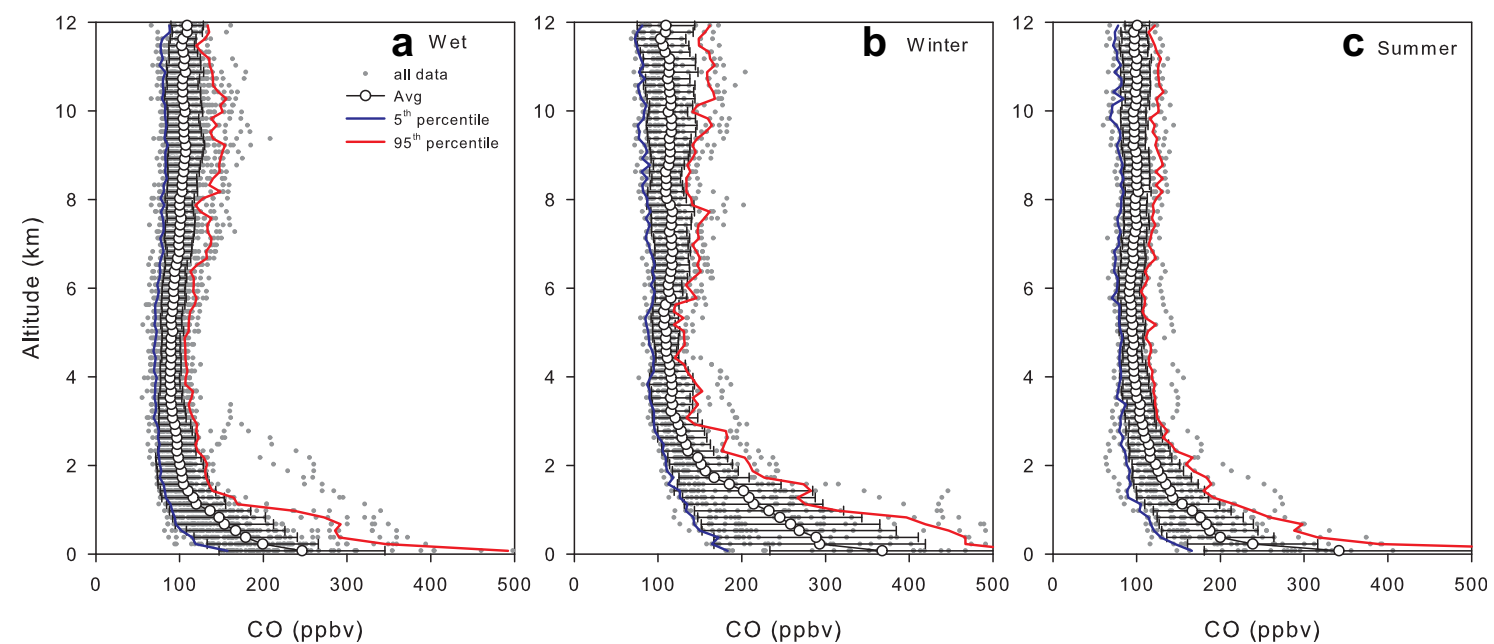

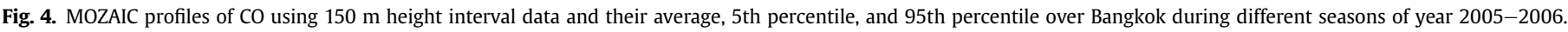

Table 1

The averages of 5th-95th percentiles of CO mixing ratio in the lower, middle and upper troposphere in three different seasons over Bangkok.

\begin{tabular}{llll}
\hline Altitude $(\mathrm{km})$ & \multicolumn{3}{l}{5 th-95th percentiles range of CO (ppbv) } \\
\cline { 2 - 4 } & Wet season & Winter season & Summer season \\
\hline $0-2$ & $97-238$ & $135-390$ & $113-285$ \\
$2-6$ & $72-114$ & $94-160$ & $80-115$ \\
$6-12$ & $80-136$ & $83-158$ & $78-123$ \\
\hline
\end{tabular}

mixing ratio of $\mathrm{CO}$ showed some enhancements and $\mathrm{CO}$ increased slightly with the altitude. In winter season, the variation in CO was largest throughout the troposphere. In this season, the average mixing ratio of $\mathrm{CO}$ decreased from $\sim 370 \mathrm{ppbv}$ near the surface to $130 \mathrm{ppbv}$ at $2 \mathrm{~km}$ of altitude. In this season, the mixing ratio of CO was lowest with a nearly constant value of about $105 \mathrm{ppbv}$ in the middle troposphere. Similar to the features seen in the wet season, the mixing ratio of $\mathrm{CO}$ showed some enhancements in the middle and upper troposphere. In summer season, the mixing ratio of $\mathrm{CO}$ varied considerably in the lower troposphere $(0-2 \mathrm{~km})$ but showed little variation in the free troposphere. In this season, the mixing ratio of CO decreases from $\sim 340$ ppbv near the surface to $115 \mathrm{ppbv}$ at $2 \mathrm{~km}$ of the altitude. In the free troposphere, the average profile of CO does not show any trend with altitude and remains constant at a level of $\sim 95 \mathrm{ppbv}$ in the summer.

The separation between the two bounding profiles (5th and 95th percentiles) shows altitude dependence indicating the different ranges of vertical variability in CO over Bangkok. In each season, the mixing ratio of $\mathrm{CO}$ showed highest variability in the lower troposphere and lowest in the middle troposphere. In the upper troposphere, the variability in the mixing ratio of $\mathrm{CO}$ was moderate but increased with altitude particularly in the wet and winter seasons. The seasonal averages of 5th-95th percentiles of CO mixing ratio in the different regions of troposphere over Bangkok are presented in Table 1.

Based on the definition presented in several studies (Sahu et al., 2009,2011 ), the profile of 5th percentile can be assumed as background profile of $\mathrm{CO}$ in the troposphere. It is to be noticed, however, that the definition of the "background" is not very strict and may vary from study to study. In the lower troposphere, the background level of $\mathrm{CO}$ decreased with an increase in altitude. In the free troposphere, the background profiles remained almost constant with average values of $77 \pm 5$ ppbv, $90 \pm 8$ ppbv, $80 \pm 5$ ppbv in the wet, winter and summer seasons, respectively.

The average profiles of CO from MOZAIC observations and MOZART simulations over Bangkok for the three different seasons are shown in Fig. 5. The MOZART-2 simulation tends to
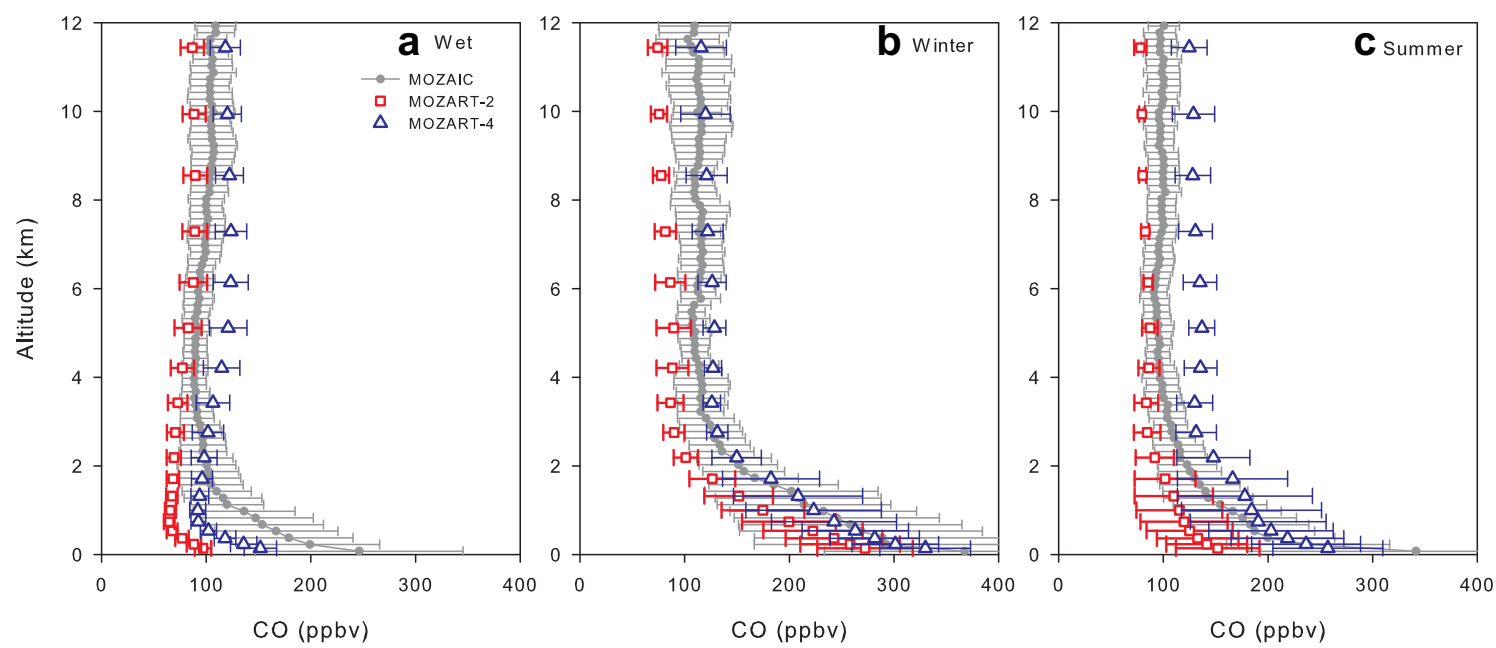

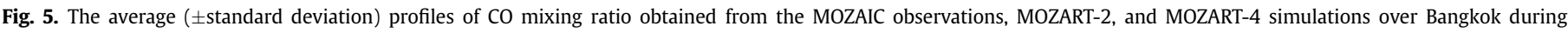
different seasons of year 2005-2006. 
underestimate the observations in all seasons. The comparison between the model and observation showed significant disagreement in the lower troposphere but gets better in the free troposphere. In comparison to MOZAIC data the MOZART-2 simulations were lower by $48 \%, 16 \%$, and $30 \%$ in the wet, winter, and summer seasons, respectively in the lower troposphere. In the free troposphere, the differences were within $15 \%, 27 \%$, and $15 \%$ in the wet, winter, and summer seasons, respectively. The MOZART-4 simulations in the lower troposphere also underestimated the observation by $23 \%$ in the wet season. On the other hand, MOZART- 4 overestimated slightly by $5 \%$ and $13 \%$ during winter and summer seasons, respectively. In the free troposphere, MOZART-4 consistently overestimated the MOZAIC observations by $18 \%, 8 \%$, and $32 \%$, during the wet, winter, and summer seasons, respectively. In the summer seasons, MOZART- 4 shows a positive bias of 7-16 ppbv in the CO total column amount over SE Asia indicating high CO
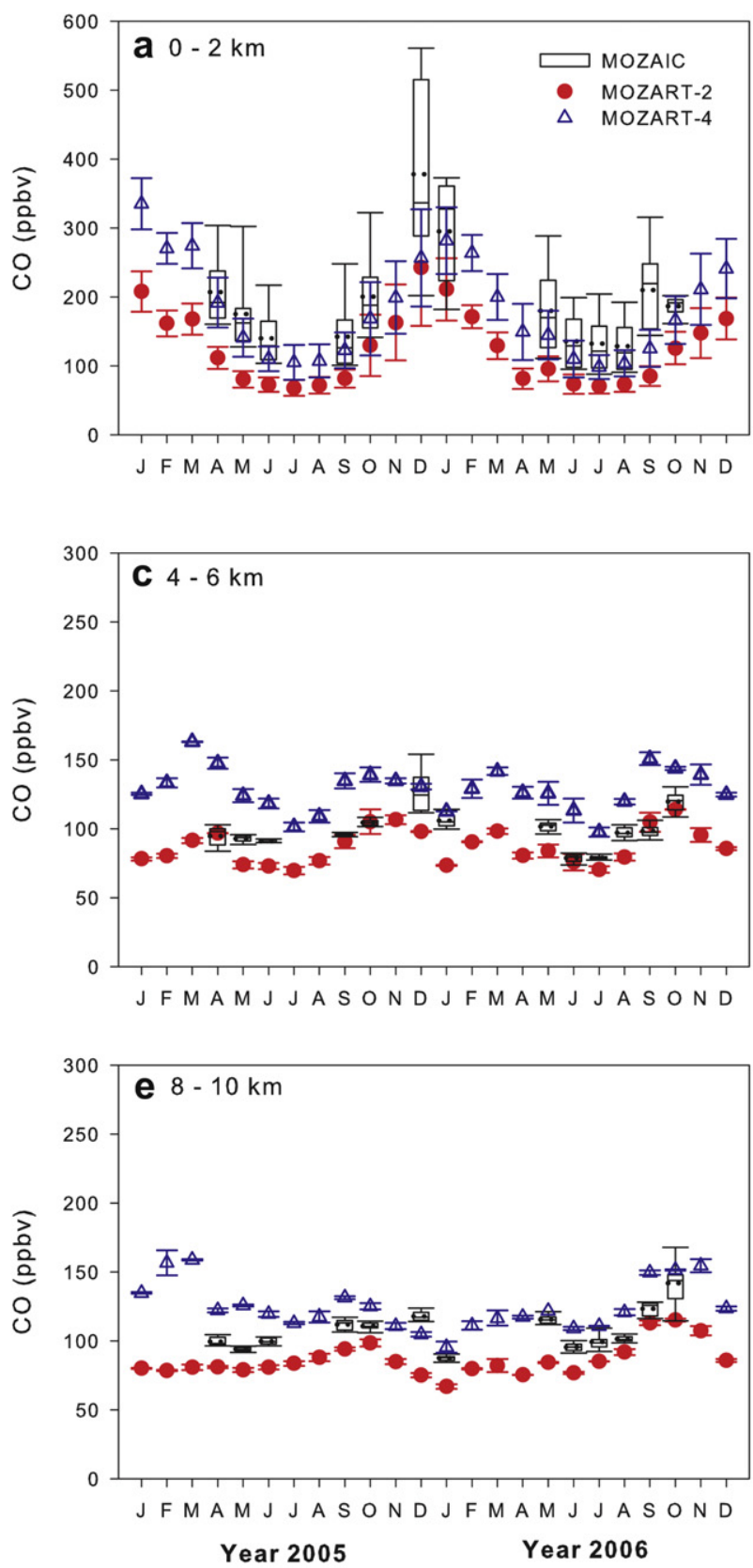

emissions from biomass burning (Emmons et al., 2010). A similar over-estimations of CO by MOZART-4 were observed in the free troposphere over Indonesia in October-November, 2006 (Srivastava and Sheel, 2013).

In this discussion we have compared the average profiles, but for the CO mixing ratios near to surface both MOZART-2 and MOZART4 tend to underestimate the MOZAIC observations. For the profiles very near to the surface, both the simulations show rapid decline of $\mathrm{CO}$ with altitude compared to MOZAIC observations particularly in the wet season. In summary, the MOZART-4 simulation provided better representation of $\mathrm{CO}$ observed over Bangkok. The significant disagreement between observation and model in the lower troposphere could partly be attributed to rather coarse resolution of MOZART. The lack of proper representation of emission and local dynamical processes over Bangkok can also be important factors. The mixing ratio of $\mathrm{CO}$ in Bangkok shows significant diurnal
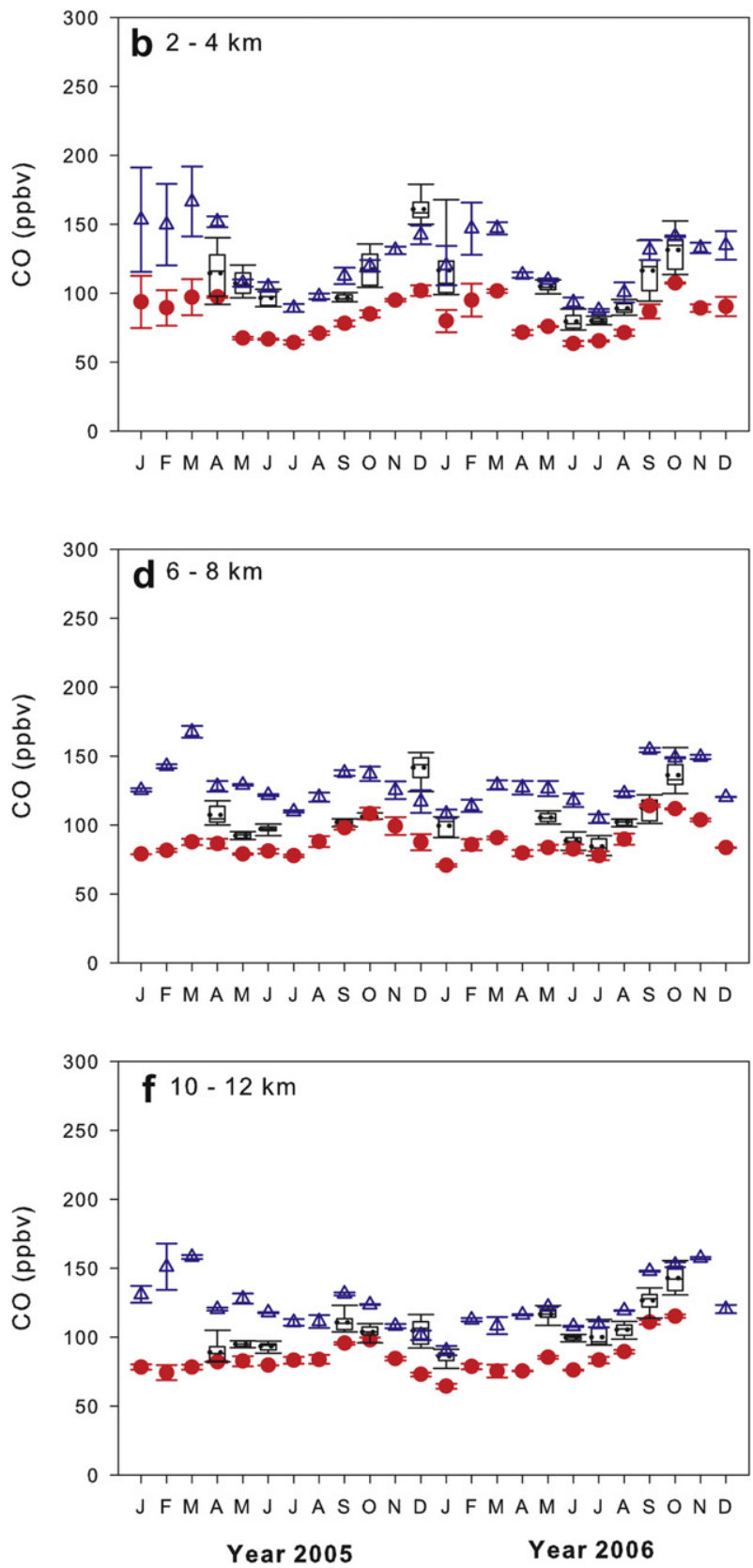

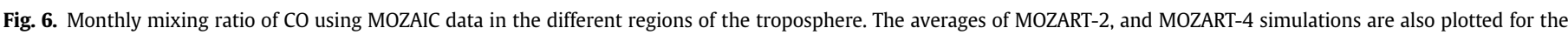
comparison. 
variation but profiles were measured at specific time of day (Sahu et al., 2011; Nedelec et al., 2003). In the lower troposphere, the range of $1 \sigma$ variance in $\mathrm{CO}$ mixing ratios might also be due to the diurnal variability of $\mathrm{CO}$ in Bangkok. In this region, the large negative bias between MOZART and MOZAIC in the wet season is due to much higher production of $\mathrm{OH}$. In the free troposphere, the difference in MOZART-2 and MOZART- 4 could be due to less $\mathrm{OH}$ formation in MOZART-4 and hence relatively less CO is lost through oxidation. In fact, it has been noticed that MOZART-4 simulated $\mathrm{OH}$ is somewhat lower than the climatology for the tropical regions (Emmons et al., 2010).

\subsection{Seasonal characteristics of $\mathrm{CO}$}

The box-whisker plots representing monthly statistics of $\mathrm{CO}$ observed in the different regions of the troposphere $(0-2 \mathrm{~km}, 2-$ $4 \mathrm{~km}, 4-6 \mathrm{~km}, 6-8 \mathrm{~km}, 8-10 \mathrm{~km}$, and $10-12 \mathrm{~km}$ ) over Bangkok during 2005-2006 are shown in Fig. 6. The observed mixing ratio of $\mathrm{CO}$ exhibits clear seasonal and inter-annual variability. The mixing ratio of $\mathrm{CO}$ was lowest in wet season and high in winter season. The seasonal variation was strongest in the lower troposphere, while the strength of seasonality decreased with the increasing altitude. In the lower troposphere, the mixing ratio of $\mathrm{CO}$ shows large variation during each month as can be seen from the levels of different percentiles. In the lower and middle troposphere, the monthly mixing ratios of $\mathrm{CO}$ show minima in the month of July and maxima in December during composite years of 2005-2006. In the lower troposphere, the mixing ratios of CO were $142 \pm 50 \mathrm{ppbv}$ and $210 \pm 60$ ppbv in September month of years 2005 and 2006, respectively. In the upper troposphere, the minima occurred in the month of July but maxima were observed in the October month of 2006 . The observed monthly ranges of $\mathrm{CO}$ were $128-378 \mathrm{ppbv}, 80$ 160 ppbv, 80-128 ppbv, 85-142 ppbv, 87-141 ppbv, and 88146 ppbv at $0-2 \mathrm{~km}, 2-4 \mathrm{~km}, 4-6 \mathrm{~km}, 6-8 \mathrm{~km}, 8-10 \mathrm{~km}$, and $10-12 \mathrm{~km}$ of altitudes, respectively.

In Fig. 6, the monthly averages of MOZART-2 and MOZART-4 simulations are also plotted for the comparison. The monthly simulations tend to capture the seasonality in CO observed in the different regions of the troposphere. Both MOZART-2 and MOZART4 underestimate the near surface $(0-2 \mathrm{~km})$ observations, however, the agreement with MOZART- 4 appears to be better. Other chemical transport models have underestimated CO in urban PBL (especially those in Asia) by as much as 39\% (Chen et al., 2009) due to the coarse resolution. In the free troposphere, most of the observed data fall between the two simulations representing the underestimation and overestimation by MOZART- 2 and MOZART-4, respectively. In the upper troposphere (6-12 km of altitudes), both the observed and simulated monthly mixing ratios of CO during September-November of year 2006 were higher by $15-30$ ppbv compared to the same period of year 2005. However, depending on the regions of the troposphere, the ratios of $\mathrm{CO}_{\mathrm{MOZART}-2} / \mathrm{CO}_{\mathrm{MO}}$

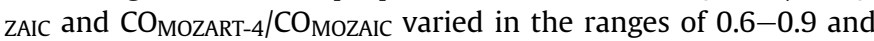
$0.8-1.3$, respectively.

The contributions of $\mathrm{CO}$ over Bangkok from the anthropogenic sources in China and BB in S-SE Asia using MOZART-4 simulations are estimated for the year 2006 (see Fig. 7). The mixing ratios of $\mathrm{CO}$ over Bangkok from both these sources showed clear seasonality. In the lower troposphere, the contribution from the anthropogenic sources in China in winter is much higher compared to those calculated for the other seasons. In the upper troposphere, however except for the wet season, the MOZART-4 simulations reveal significant contribution of $\mathrm{CO}$ from anthropogenic sources in China. The impact of BB activities in S-SE Asia in winter season was confined mostly in the lower troposphere. The BB emission in S-SE Asia provides major contribution to $\mathrm{CO}$ in the free troposphere from
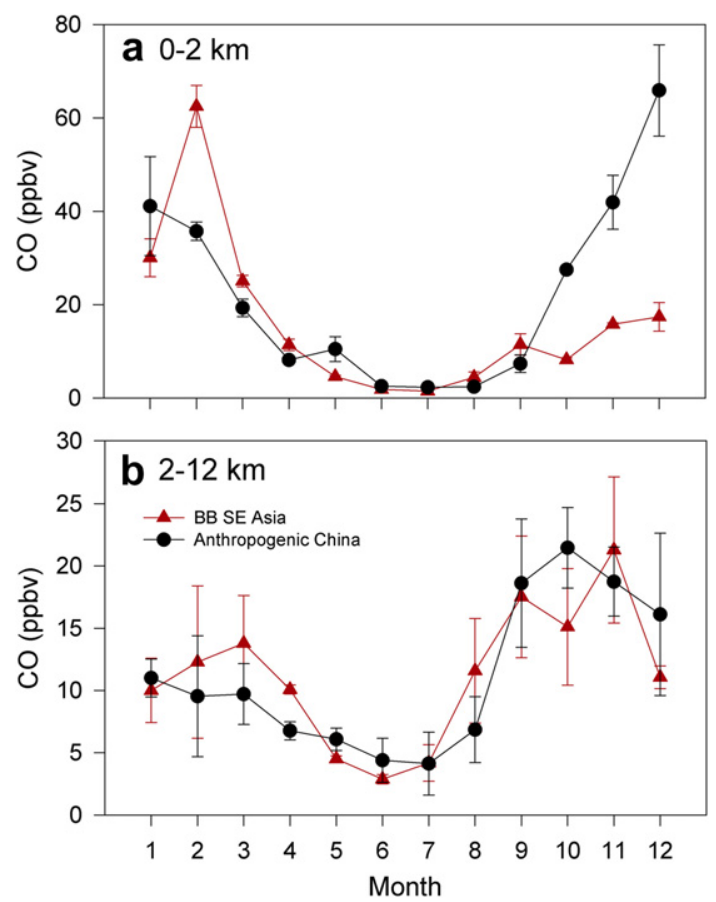

Fig. 7. Monthly contributions of CO estimated using the MOZART-4 simulations over Bangkok from BB in S-SE Asia and anthropogenic sources in China.

September to December, mainly associated with the forest fires in Indonesian and Malaysian islands.

\section{Discussion}

\subsection{Biomass burning emissions and long-range transport}

Emissions of CO from global BB sources show strong seasonal and inter-annual variations (van der Werf et al., 2006). In this study, we have used the fire count data detected by the Along Track Scanning Radiometer (ATSR). Details of the ATSR methodologies can be found elsewhere (Buongiorno et al., 1997; Arino et al., 2001). The seasonal maps of fire counts detected over S-SE Asia during the years 2005 and 2006 are shown in Fig. 8. In the wet season, however which is dry season in the southern hemisphere regions of Asia, the fire count data shows major BB activities only in the southern regions of $\mathrm{S}-\mathrm{SE}$ Asia. The fires in the forested regions make the highest contribution among the other BB sources in Indonesia. The BB activities in Indonesian islands during year 2006 were significantly high compared to those during year 2005. Both the MOZAIC observations and MOZART simulations of CO over Bangkok during late wet season show the impact of extensive BB in Indonesia during year 2006.

In the winter season, the major activities of $B B$ shift to the northern hemisphere regions of SE Asia most prominently in Thailand and Burma. In addition to BB in S-SE Asia in winter, many hot spots can be located in the far upwind over the southeast of China. The BB in Indonesia remained active till NovemberDecember of each year. In this season (winter), the BB activities in Thailand during year 2006 were significantly low compared to those during year 2005. The fire count maps during summer of both the years exhibit wide spread activities of BB in the S-SE Asia mostly over northern India, Pakistan, Burma, Laos and northern Thailand. Also in this season, the density of hot spots detected in Thailand during the summer of year 2006 was lesser than those during the year 2005 . 

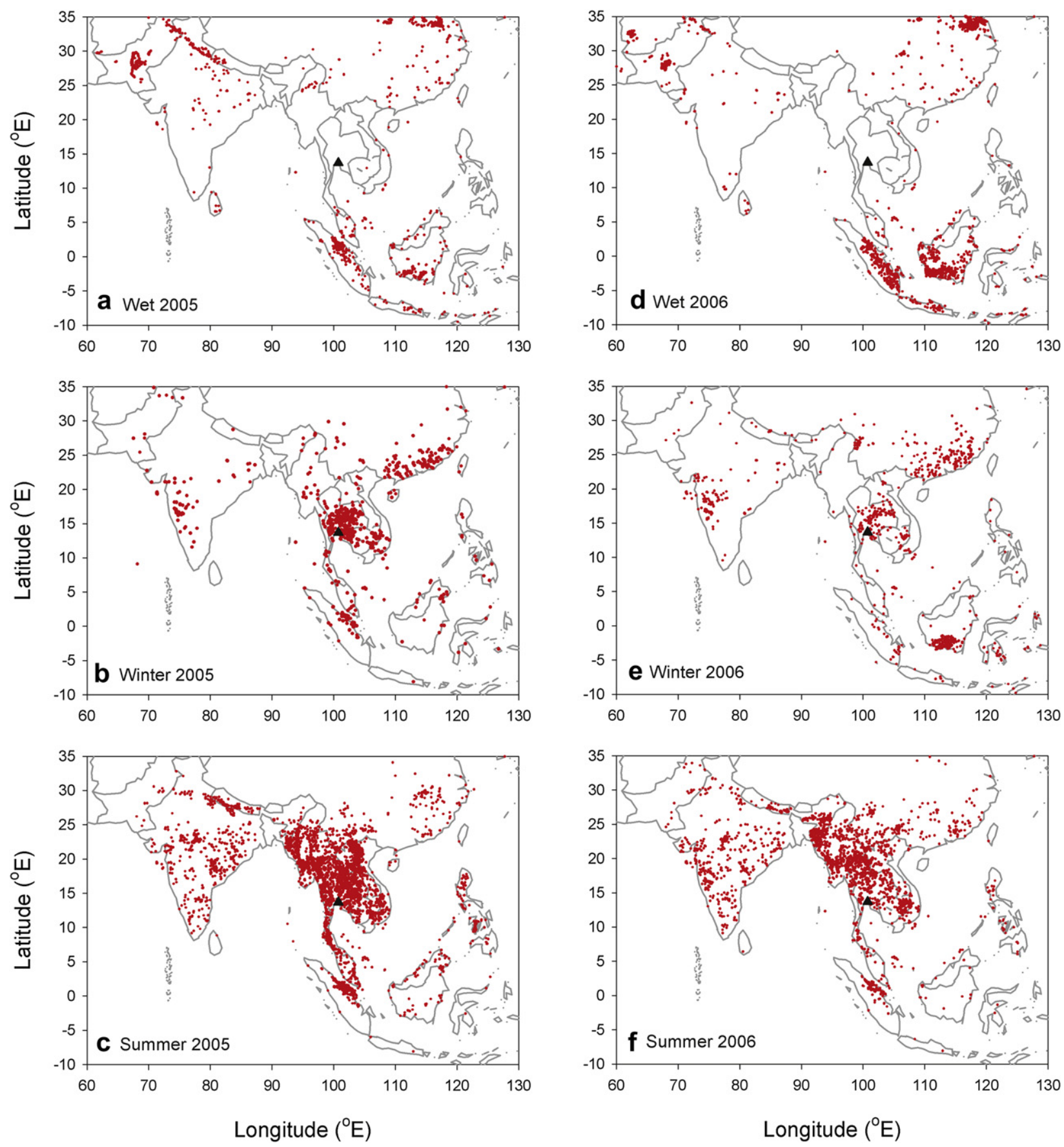

Fig. 8. Maps of ATSR fire count data detected over south and Southeast Asia (S-SE Asia) during different seasons of year 2005 and 2006.

The monthly fire count data detected over different countries in SSE Asia during year 2005 and 2006 are plotted in Fig. 9. In all countries of northern hemisphere of S-SE Asia the BB emissions are significant during February-May when relatively dry weather prevails. The highest BB in Thailand was during the months of February-March. In India, the BB occurs from February to May but the month of April experiences the highest activities. From Mid of June to October the activities shift toward SE Asia when activities are only due to the fires in Indonesian and Malaysian islands. In summary, the analysis of fire count data reveals systematic seasonal and inter-annual variations in BB emissions over S-SE Asia. However, the roles of CO emitted from $\mathrm{BB}$ and anthropogenic sources in different regions of S-SE Asia on the vertical distribution of CO over Bangkok can be ascertained by incorporating the seasonality in the long-range transport.

Back trajectory models have been widely used to track the transport of air parcels originated from different source regions. In this study, the isentropic back trajectories were calculated using the Japanese 25-year Reanalysis data (JRA-25, 6 h, $1.25 \times 1.25$; Onogi et al., 2007) with the same advection algorithm as Draxler and Hess (1997). The trajectories were calculated for a total run time of $168 \mathrm{~h}$ ( 7 days) at $1 \mathrm{~km}, 5 \mathrm{~km}$ and $10 \mathrm{~km}$ of altitudes with a time step of $5 \mathrm{~min}$. For both the year of 2005 and 2006, the origins and pathways of trajectories arriving over Bangkok (at $1 \mathrm{~km}$ of altitude) show very clear and systematic seasonality (Fig. 10). We have not 


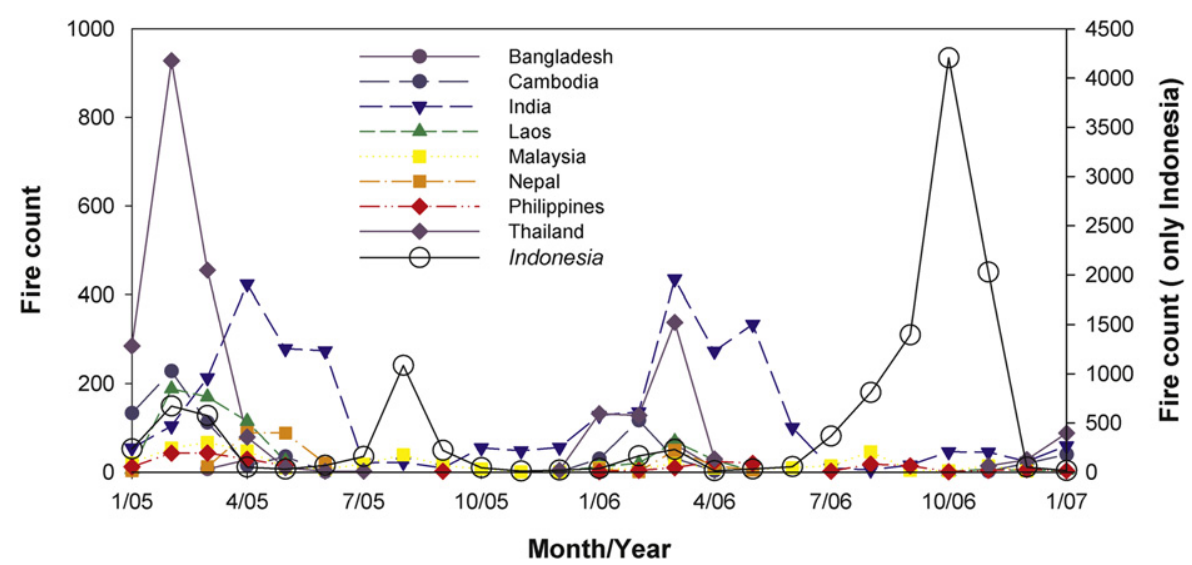

Fig. 9. The monthly variation of fire count data detected over different countries in S-SE Asia during year 2005-2006.
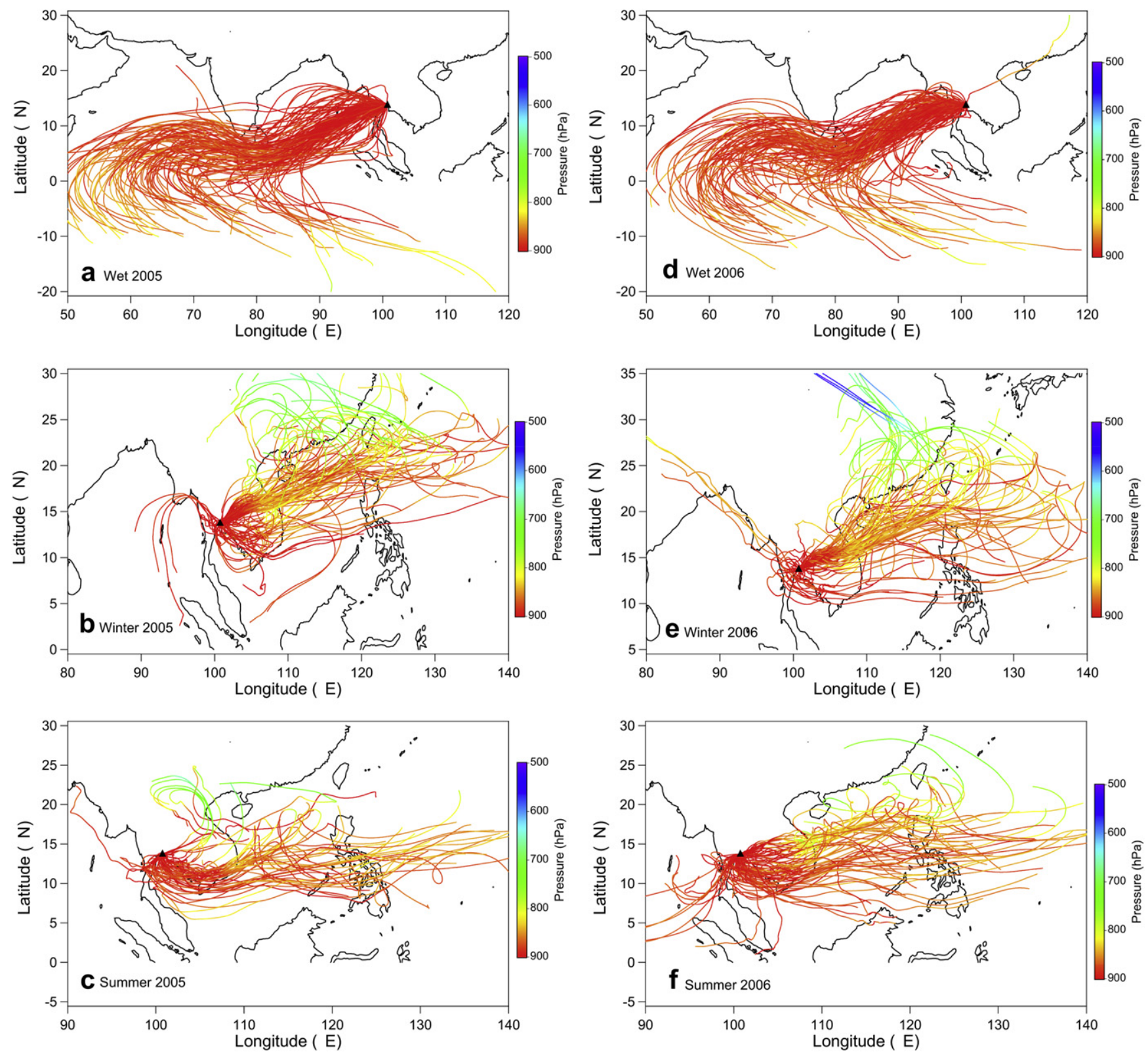

Fig. 10. Back trajectory plots at $1 \mathrm{~km}$ over Bangkok (triangle symbol) during different seasons of year 2005 and 2006. 
shown the trajectories at 5 and $10 \mathrm{~km}$, however, we have briefly discussed the seasonality in trajectories also at these two altitudes.

In the wet season, the site is influenced by the cleaner air from the southern Indian Ocean due to the long-range transport from the SW direction. In the lower troposphere, the ambient pressure along the trajectories suggests that the air masses were confined within the marine boundary layer (MBL) of the Indian Ocean before they arrived over Bangkok. In addition to the negligible presence of $\mathrm{BB}$ sources in the wet season, the flow of cleaner marine air could be the major cause for the low $\mathrm{CO}$ observed in the wet season. The trajectories at $5 \mathrm{~km}$ of altitude originated over the Arabian Sea and Bay of Bengal and did not pass through major source regions. On the other hand, the trajectories arriving at $10 \mathrm{~km}$ of altitude were originated over the East China Sea and had passed over the southeast regions of China before entering in SE Asia. In the absence of $\mathrm{BB}$ the anthropogenic activities in northern hemisphere regions of SE Asia can be dominant source of CO. Additionally, the transport of $\mathrm{CO}$ from both anthropogenic and BB sources in southeast of China could be the cause of enhanced $\mathrm{CO}$ in the upper troposphere during the wet season.

In winter the back trajectories show the impact of long-range transport of continental air from the NE direction in the lower troposphere. The trajectories at $1 \mathrm{~km}$ of altitude were traced to have originated in the free troposphere over the eastern continental regions of China where activities of $\mathrm{BB}$ were significant. In the middle troposphere, the trajectories (at $5 \mathrm{~km}$ of altitude) show the predominance of air mass originated over the Pacific Ocean, however some trajectories originated or passed over the IndoGangetic Plain (IGP). The mid-tropospheric level of CO in winter was higher compared those observed in other seasons. In winter, relatively higher levels of $\mathrm{CO}$ in the middle troposphere could be due to the transport of polluted air from IGP. In the upper troposphere, the back trajectories were originated over Pacific Ocean and passed through the fire active regions of Indonesia islands. Therefore, the enhancements in upper tropospheric CO particularly during October of year 2006 could be attributed to the extensive BB in Indonesia. Supporting the impact of extensive BB in Indonesia in the upper tropospheric CO over Bangkok, the Microwave Limb Sounder (MLS) data averaged over 100 E-125 E of longitudes show widespread enhancements in the mixing ratios of $\mathrm{CO}$ at $215 \mathrm{hpa}$ ( $\sim 11 \mathrm{~km}$ ) between $20 \mathrm{~S}$ and $20 \mathrm{~N}$ of latitudes (Zhang et al., 2011). Similarly, very high CO concentrations in the middle to upper troposphere $(400-200 \mathrm{hPa})$ were also observed by the Atmospheric Chemistry Fourier Transform Spectrometer (ACEFTS) and by the MOPITT instrument (Yurganov et al., 2008) over the same region during Indonesian fires in the year 2006.

In the summer season, the trajectories were originated over the Pacific Ocean and arrived over Bangkok from the SE and SW directions in the lower troposphere. The activities of BB were most extensive in many parts of SE Asia during this season. However unexpectedly, the mixing ratio of $\mathrm{CO}$ throughout the troposphere was lower compared to those measured during the winter season. The analyses of fire count data and back trajectories suggest that the impact of strong emissions in the summer season were subdued by the dilution due to mixing with cleaner and from Pacific and Indian Oceans. In other words, the wind flow from the SE/SW directions in the lower troposphere diluted the impact of local emissions significantly. In the upper troposphere, the trajectories were traced to have originated over the Indian Ocean hence the enhancements in $\mathrm{CO}$ were not significant compared to those observed in two other seasons over Bangkok.

\subsection{Impact of local wind on seasonality of CO in lower troposphere}

Aside from local emissions, levels of CO are influenced by meteorology, coastal and urban effects and trans-boundary transport in the lower troposphere. However, to estimate the contributions of different factors require detailed studies using regional scale models. Nonetheless, variations in meteorological parameters were observed to play important role in the distribution of primary pollutants in many urban areas. For instance, the local wind can significantly influence the mixing ratios of various pollutants. Sahu et al. (2011) have shown that the surface concentrations of black carbon (BC) and organic carbon (OC) aerosols in Bangkok show strong dependencies with the wind speed.

In this study, we investigated the dependence of $\mathrm{CO}$ mixing ratio on wind speed in the lower troposphere $(<2 \mathrm{~km})$. The polar plots of wind parameters, color-coded with the mixing ratio of $\mathrm{CO}$, for the three different seasons are shown in Fig. 11. As shown in Fig. 11(a), the observations were mostly influenced by the strong winds $(0-$ $20 \mathrm{~m} \mathrm{~s}^{-1}$ ) from the SW direction in the wet season. This flow of cleaner marine air could have caused significant dilution of $\mathrm{CO}$ emitted from Bangkok city. However occasionally in this season, the higher levels of $\mathrm{CO}$ were observed during the episodes of stagnant air mass originated from the N-NE directions. In the winter season, rather weak winds from the NW-NE and NE-SE sectors dominated in the lower troposphere over Bangkok (see Fig. 11(b)). The influence of dilution was less pronounced as the
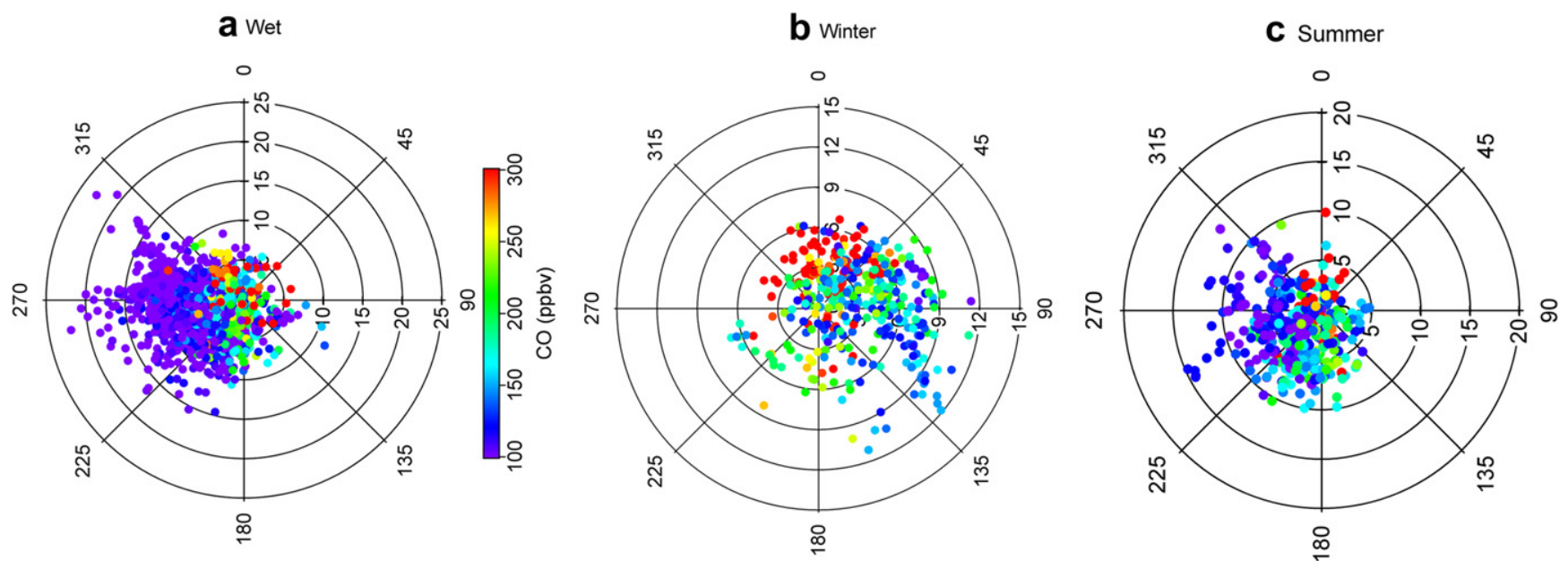

Fig. 11. Polar plots of wind parameters (wind speed $\left(\mathrm{m} \mathrm{s}^{-1}\right)$ and wind direction (deg.)) over Bangkok during different seasons of year $2005-2006$. 
Table 2

Statistics (average \pm standard deviation) of $\mathrm{CO}$ and meteorological parameters in different wind sectors in the lower troposphere $(<2 \mathrm{~km}$ of altitudes) over Bangkok.

\begin{tabular}{lllll}
\hline $\begin{array}{l}\text { Wind } \\
\text { sector }\end{array}$ & $\begin{array}{l}\text { Wind speed } \\
\left(\mathrm{m} \mathrm{s}^{-1}\right)\end{array}$ & $\begin{array}{l}\text { Temperature } \\
\left({ }^{\circ} \mathrm{C}\right)\end{array}$ & $\begin{array}{l}\text { Relative } \\
\text { humidity }(\%)\end{array}$ & $\begin{array}{l}\text { CO } \\
(\mathrm{ppbv})\end{array}$ \\
\hline N-NE & $3.5 \pm 1.7$ & $22.4 \pm 6$ & $71 \pm 19$ & $247 \pm 132$ \\
E-NE & $4.8 \pm 2.3$ & $20.1 \pm 5$ & $78 \pm 14$ & $190 \pm 75$ \\
E-SE & $5.4 \pm 2.8$ & $20.1 \pm 5$ & $83 \pm 12$ & $165 \pm 58$ \\
S-SE & $4.5 \pm 2.3$ & $23.2 \pm 4$ & $74 \pm 15$ & $187 \pm 72$ \\
S-SW & $5.7 \pm 2.7$ & $22.4 \pm 5$ & $78 \pm 12$ & $157 \pm 61$ \\
W-SW & $7.3 \pm 2.7$ & $20.0 \pm 4$ & $82 \pm 10$ & $124 \pm 48$ \\
W-NW & $7.8 \pm 4.3$ & $20.1 \pm 5$ & $79 \pm 12$ & $125 \pm 70$ \\
N-NW & $4.2 \pm 2.1$ & $22.2 \pm 5$ & $74 \pm 16$ & $234 \pm 127$ \\
\hline
\end{tabular}
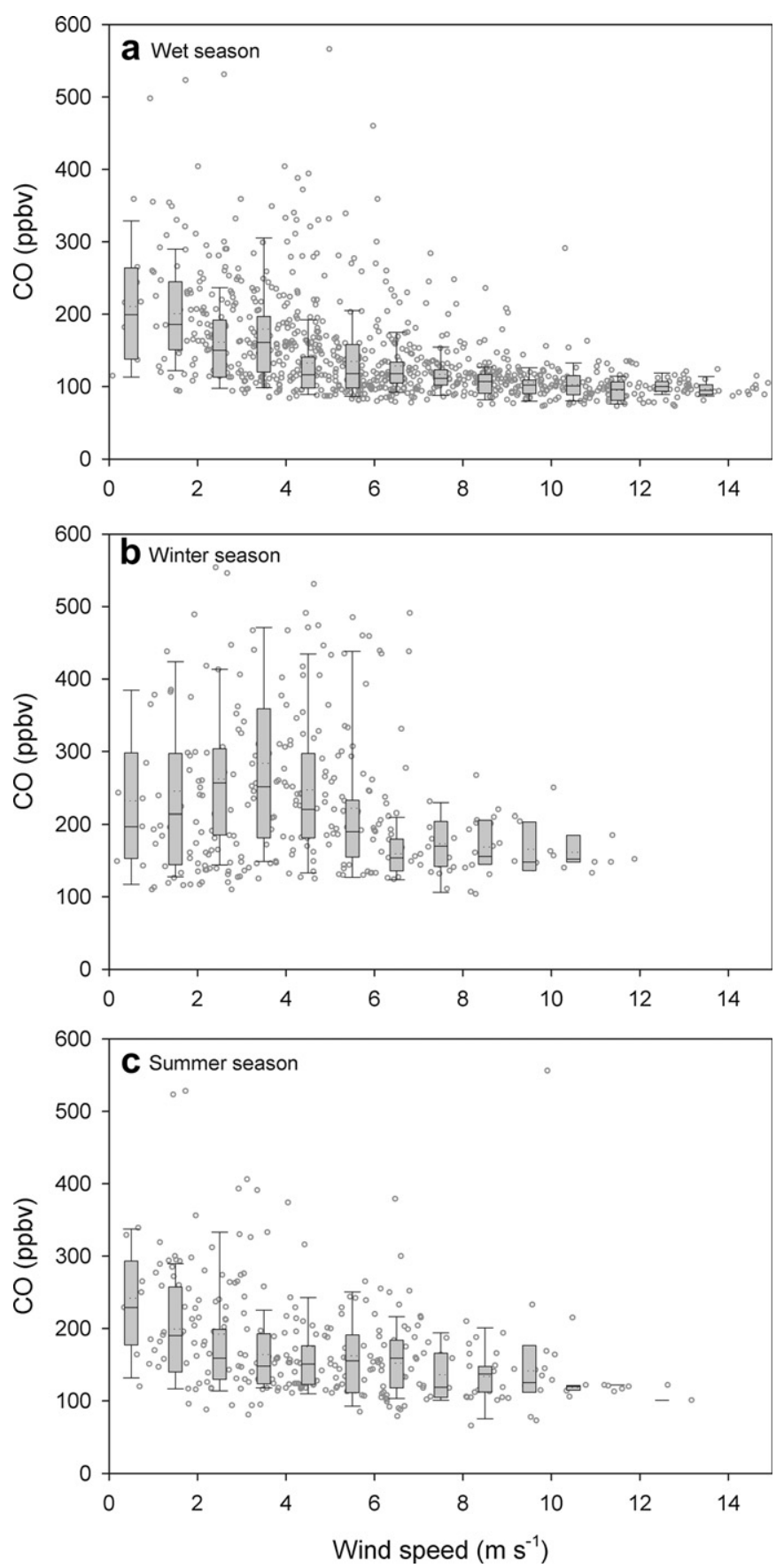

Fig. 12. The scatter and box-whisker plots show the dependencies of the mixing ratio of $\mathrm{CO}$ on wind speed during the wet, winter and summer seasons. mixing ratio of CO remained high under stagnant conditions ( $0-$ $6 \mathrm{~m} \mathrm{~s}^{-1}$ ) of continental air from the NW-NE sectors in winter. In the summer season, the winds from S-SW directions transport cleaner air from the Gulf Thailand and Indian Ocean and dilute the mixing ratio of CO significantly (see Fig. 11(c)). Like other seasons, some enhancements in $\mathrm{CO}$ were observed under stagnant weather conditions in the summer season. Statistics (average \pm standard deviation) of $\mathrm{CO}$ and meteorological parameters in different wind sectors in the lower troposphere over Bangkok are presented in Table 2. During the N-NE wind flow, the mixing ratio of $\mathrm{CO}$ was highest of $247 \pm 132 \mathrm{ppbv}$ and wind speed was recorded to be lowest $\left(3.5 \pm 1.7 \mathrm{~m} \mathrm{~s}^{-1}\right)$. In the N-NE sector, the mixing ratio of $\mathrm{CO}$ was lowest of $124 \pm 48$ ppbv which coincided with the strong wind flow of $7.3 \pm 2.7 \mathrm{~m} \mathrm{~s}^{-1}$.

The dependencies of $\mathrm{CO}$ on the magnitude of wind speed for different seasons are shown in Fig. 12. The CO-wind relation varies with the season and magnitude of the wind (regimes), overall the mixing ratio of $\mathrm{CO}$ decreases with the increasing wind speed. In the lower wind speed regime $\left(<5 \mathrm{~m} \mathrm{~s}^{-1}\right)$, CO decreases sharply with increasing wind speed in the wet and summer seasons. During these two seasons, the mixing of air from Indian and Pacific Oceans having low levels of CO resulted in sharp decrease CO over Bangkok. In the winter season, the mixing ratio of $\mathrm{CO}$ tends to increase with the magnitude of wind in the low wind regime. In the winter season, the prevailing long-range transport brings continental pollutants with elevated background of $\mathrm{CO}$ from NE and NW directions. In the higher wind flow regimes $\left(>5 \mathrm{~m} \mathrm{~s}^{-1}\right)$, the mixing ratios of $\mathrm{CO}$ were lowest and also show weaker dependence with the wind speed.

Although not shown in this study, the regression analysis of average $\mathrm{CO}$ versus wind speed (averaged for a bin of $1.0 \mathrm{~m} \mathrm{~s}^{-1}$ ) data shows very good linear fits with correlation coefficient $\left(r^{2}\right)$ values of $0.88,0.89$ and 0.95 during the wet, winter and summer seasons, respectively. The slopes of $\Delta \mathrm{CO} / \Delta$ wind speed

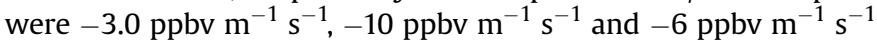
during the wet, winter and summers seasons, respectively. The mixing ratio of $\mathrm{CO}$ does not exhibit significant relation with wind speed in the middle and upper troposphere over Bangkok.

\section{Summary and conclusions}

Study of tropospheric mixing ratio of CO over Bangkok, Thailand has been presented based on the MOZAIC aircraft profile data measured during the year 2005 and 2006. We have investigated the causes of seasonality in the vertical distribution of CO by analyzing the back trajectory, ATSR fire count and meteorological data. We have also used MOZART simulations for the comparison with the observations. In Thailand, the three different seasons viz. wet, winter, and summer are linked to the variations in meteorological parameters and monsoonal transport. The meteorological parameters such as wind speed, $\mathrm{RH}$, and precipitation showed lows and highs during the winter and wet seasons, respectively.

The observations in the lower troposphere were influenced by the flow of cleaner air due to prevailing SW monsoon in the wet season, while NE flow brings continental pollutants during the winter. The mixed air originated from different regions of SE Asia and cleaner air from surrounding marine regions prevailed in the summer season. The trajectories arriving at $5 \mathrm{~km}$ of altitude did not pass through major source regions except IGP in the winter. The back trajectories at $10 \mathrm{~km}$ were originated over Pacific Ocean and passed through the fire active regions of Indonesia islands during winter season. In the free troposphere, the background mixing ratios of $\mathrm{CO}$ were estimated to be $\sim 77 \mathrm{ppbv}, 90 \mathrm{ppbv}, 80 \mathrm{ppbv}$ in the wet, winter and summer seasons, respectively.

In the wet season, the major activities of $\mathrm{BB}$ were located in the southern hemisphere regions of S-SE Asia. In the winter 
season, the major activities of $\mathrm{BB}$ shift to the northern hemisphere regions of SE Asia and many hot spots were also located in the far upwind over the southeast China. The activities of BB during summer were extensive and wide spread in the S-SE Asia. The large scale phenomena like El Niño can impact the BB emissions in SE Asia year as 2005 was a normal year but year 2006 was an El Niño year.

The mixing ratio of $\mathrm{CO}$ was highest in the lower atmosphere and lowest in the middle troposphere during all the seasons. The average mixing ratios of $\mathrm{CO}$ near the surface were $\sim 250 \mathrm{ppbv}$, 370 ppbv and 340 ppbv during the wet, winter and summer seasons, respectively. In the free troposphere, the profiles remains almost constant with average values of $77 \pm 5 \mathrm{ppbv}, 90 \pm 8 \mathrm{ppbv}$, $80 \pm 5$ ppbv in the wet, winter and summer seasons, respectively. In the upper troposphere, the mixing ratio of CO shows significant enhancements particularly during wet and winter seasons.

The observed monthly mixing ratio of $\mathrm{CO}$ exhibits clear seasonal and inter-annual variability in the different regions of the troposphere. In the lower and middle troposphere, CO shows minima in July and maxima in December. In the upper troposphere, the minima occur in the month of July but maxima were observed in the October month of 2006. In the lower troposphere, the mixing ratio of CO was $\sim 70$ ppbv higher in September 2006 compared to same month year 2005. In the upper troposphere, the monthly mixing ratios of CO during September-November of year 2006 were higher by $15-30$ ppbv compared to the same period of year 2005. The enhancements in tropospheric CO during the wet season of year 2006 can be attributed to the extensive forest fire in Indonesia.

In the lower troposphere, both the MOZART simulations underestimate the observations but the agreement with MOZART-4 appears to be better. In the free troposphere, the observations lie between the two simulations representing the underestimation and overestimation by MOZART-2 and MOZART-4, respectively. Depending on the altitude, the ratios of $\mathrm{CO}_{\text {MOZART-2 }} / \mathrm{CO}_{\text {MOZAIC }}$ and

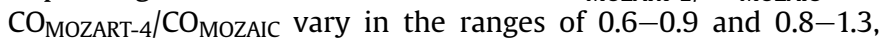
respectively. The mixing ratio of $\mathrm{CO}$ depends on the magnitude of local wind speed in the lower troposphere but no clear dependencies were seen in the free troposphere. The relationship between $\mathrm{CO}$ and wind speed varies with the season and magnitude of the wind. Overall the mixing ratio of $\mathrm{CO}$ decreases with the increasing wind speed.

\section{Acknowledgments}

The authors acknowledge for their strong support the European Commission, Airbus, CNRS-France, FZJ-Germany and the airlines (Lufthansa, Air France, Austrian and former Sabena who carry free of charge the MOZAIC instrumentation since 1994). The ATSR World Fire Atlas data has been taken from Ionia products of European Space Agency.

\section{References}

Allen, et al., 1999. Observations of middle atmosphere CO from the UARS ISAMS during the early northern winter 1991/92. Journal of the Atmospheric Sciences 56, 563-583.

Arino, O., Simon, M. Piccolini, I., Rosaz, JM. 2001. The ERS-2 ATSR-2 World Fire Atlas and the ERS-2 ATSR-2 World Burnt Surface Atlas Projects, Paper Presented at 8th ISPRS Conference on Physical Measurement and Signatures in Remote Sensing. European Space Agency, Aussois, France.

Asnani, G.C., 1993. Climatology of the tropics. In: Tropical Meteorology, 1. Indian Institute of Tropical Meteorology, Pune, India, pp. 100-204.

Bangkok Metropolitan Administration (BMA), Green Leaf Foundation and United Nations Environment Programme, 2009. Bangkok Assessment Report on Climate Change 2009. BMA, GLF and UNEP, Bangkok.

Buongiorno, A., Arino, O., Zehner, C., Colagrande, P., Goryl, P., 1997. ERS-2 monitors exceptional fire event. Earth Observation Quarterly 56, 1-6.
Chen, D., Wang, Y., McElroy, M.B., He, K., Yantosca, R.M., Le Sager, P., 2009. Regiona $\mathrm{CO}$ pollution and export in China simulated by the high-resolution nested-grid GEOS-Chem model. Atmospheric Chemistry and Physics 9, 3825-3839.

Chuersuwan, N., Nimrat, S., Lekphet, S., Kerdkumrai, T., 2008. Levels and major sources of $\mathrm{PM}_{2.5}$ and $\mathrm{PM}_{10}$ in Bangkok Metropolitan Region. Environment International 34, 671-677. http://dx.doi.org/10.1016/j.envint.2007.12.018.

Cooper, et al., 2004. A case study of transpacific warm conveyor belt transport: influence of merging airstreams on trace gas import to North America. Journal of Geophysical Research 109, D23S08,. http://dx.doi.org/10.1029/2003JD003624.

Department of Land Transport (DLT), 2008. Transport Statistics. http://www.dlt.go. th/statistics_web/statistics.html.

Department of Land Transport (DLT), 2010. Statistic: Number of Vehicle Registered in Bangkok as of 31 December 2010, Bangkok. http://apps.dlt.go.th/statistics_ web/vehicle.html.

Draxler, R.R., Hess, G.D., 1997. Description of the HYSPLIT_4Modeling System. NOAA Tech. Memo. ERL ARL-224, December, 24pp.

Duncan, B.N., Martin, R.V., Staudt, A.C., Yevich, R., Logan, J.A., 2003. Interannual and seasonal variability of biomass burning emissions constrained by satellite observations. Journal of Geophysical Research 108, 4100. http://dx.doi.org 10.1029/2002JD002378.

Emmons, L.K., et al., 2000. Data composites of airborne observations of tropospheric ozone and its precursors. Journal of Geophysical Research 105, 20497-20538. http://dx.doi.org/10.1029/2000JD900232.

Emmons, L.K., et al., 2010. Description and evaluation of the Model for Ozone and Related chemical Tracers, version 4 (MOZART-4). Geoscientific Model Development 3, 43-67. http://dx.doi.org/10.5194/gmd-3-43-2010.

Fishman, J., Seiler, W., 1983. Correlative nature of ozone and carbon monoxide in the troposphere: implications for the tropospheric ozone budget. Journal of Geophysical Research 88, 3662-3670. http://dx.doi.org/10.1029/JC088iC06p03662.

Granier, C., et al., 2004. Present and Future Surface Emissions of Atmospheric Compounds, European Commission Report EVK 2199900011.

Heald, C.L., Jacob, D.J., Palmer, P.I., Evans, M.J., Sachse, G.W., Singh, H.B., Blake, D.R., 2003. Biomass burning emission inventory with daily resolution: application to aircraft observations of Asian outflow. Journal of Geophysical Research 108, 8811. http://dx.doi.org/10.1029/2002JD003082.

Holloway, T., Levy II, H., Kasibhatla, P., 2000. Global distribution of carbon monoxide. Journal of Geophysical Research 105, 12123-12147.

Horowitz, L.W., et al., 2003. A global simulation of tropospheric ozone and related tracers: description and evaluation of MOZART, version 2. Journal of Geophysical Research 108, 4784. http://dx.doi.org/10.1029/2002JD002853.

Jaffe, D., Mahura, A., Kelley, J., Atkins, J., Novelli, P.C., Merrill, J., 1997. Impact of Asian emissions on the remote North Pacific atmosphere: interpretation of CO data from Shemya, Guam, Midway and Mauna Loa. Journal of Geophysical Research 102, 28627-28635. http://dx.doi.org/10.1029/96JD02750.

Lelieveld, J., et al., 2001. The Indian Ocean experiment: widespread air pollution from south and Southeast Asia. Science 291, 1031-1036.

Marenco, et al., 1998. Measurement of ozone and water vapor by Airbus in-service aircraft: the MOZAIC airborne program, an overview. Journal of Geophysical Research 103, 25631-25642.

Maynard, R.L., Waller, R., 1999. Carbon monoxide. In: Holgate, S.T., et al. (Eds.), Air Pollution and Health. Academic, San Diego, Calif, pp. 749-796.

Nedelec, et al., 2003. An improved infrared carbon monoxide analyser for routine measurements aboard commercial Airbus aircraft: technical validation and firs scientific results of the MOZAIC III programme. Atmospheric Chemistry and Physics 3, 1551-1564. http://dx.doi.org/10.5194/acp-3-1551-2003.

Novelli, P.C., Masarie, K.A., Lang, P.M., 1998. Distributions and recent changes of carbon monoxide in the lower troposphere. Journal of Geophysical Research 103, 19015-19033. http://dx.doi.org/10.1029/98JD01366.

Ohara, T., Akimoto, H., Kurokawa, J., Horii, N., Yamaji, K., Yan, X., Hayasaka, T., 2007. An Asian emission inventory of anthropogenic emission sources for the period 1980-2020. Atmospheric Chemistry and Physics 7, 4419-4444. http:// dx.doi.org/10.5194/acp-7-4419-2007.

Olivier, J.G.J., Peters, J.A.H.W., Bakker, J., Berdowski, J.J.M., Visschedijk, A.J.H., Bloos, J.P.J., 2002. Applications of EDGAR: Emission Database for Global Atmospheric Research. Report on: 410.200.051. RIVM, The Netherlands.

Olivier, J., Peters, J., Granier, C., Petron, G., Müller, J., Wallens, S., 2003. Present and Future Surface Emissions of Atmospheric Compounds. POET Report \#2, EU Project EVK21999-00011. Available at: http://www.aero.jussieu.fr/projet/ACCENT/Documents/ del2_final.doc.

Olivier, J.G.J., Van Aardenne, J.A., Dentener, F., Pagliari, V., Ganzeveld, L.N., Peters, J.A.H.W., 2005. Recent trends in global greenhouse gas emissions: regional trends 1970-2000 and spatial distribution of key sources in 2000. Environmental Sciences 2 (2-3), 81-99. http://dx.doi.org/10.1080/15693430500400345.

Onogi, K., Tsutsui, J., Koide, H., Sakamoto, M., Kobayashi, S., Hatsushika, H. Matsumoto, T., Yamazaki, N., Kamahori, H., Takahashi, K., Kadokura, S., Wada, K., Kato, K., Oyama, R., Ose, T., Mannoji, N., Taira, R., 2007. The JRA-25 reanalysis. Journal of the Meteorological Society of Japan 85 (3), 369-432.

Pochanart, P., Akimoto, H., Kajii, Y., Sukasem, P., 2003. Carbon monoxide, regionalscale transport, and biomass burning in tropical continental Southeast Asia: observations in rural Thailand. Journal of Geophysical Research 108, 4552. http://dx.doi.org/10.1029/2002JD003360.

Sahu, L.K., Lal, S., Venkataramani, S., 2006. Distributions of $\mathrm{O}_{3}$, $\mathrm{CO}$, and hydrocarbons over the Bay of Bengal: a study to assess the role of transport from southern India and marine regions during September-October 2002. Atmospheric Environment 40, 4633-4645. 
Sahu, L.K., Lal, S., 2006. Distributions of $C_{2}-C_{5}$ NMHCs and related trace gases at a tropical urban site in India. Atmospheric Environment 40, 880-891.

Sahu, L.K., Kondo, Y., Miyazaki, Y., Kuwata, M., Koike, M., Takegawa, N., Tanimoto, H., Matsueda, H., Yoon, S.C., Kim, Y.J., 2009. Anthropogenic aerosols observed in Asian continental outflow at Jeju Island, Korea, in spring 2005. Journal of Geophysical Research 114, D03301.

Sahu, L.K., Kondo, Y., Miyazaki, Y., Pongkiatkul, P., Kim Oanh, N.T., 2011. Seasonal and diurnal variations of black carbon and organic carbon aerosols in Bangkok. Journal of Geophysical Research 116, D15302. http://dx.doi.org/10.1029/2010JD015563.

Sheel, V., Lal, S., Richter, A., Burrows, J.P., 2010. Comparison of satellite observed tropospheric $\mathrm{NO}_{2}$ over India with model simulations. Atmospheric Environment 44, 3314-3321.

Shindell, D.T., et al., 2006. Multimodel simulations of carbon monoxide: comparison with observations and projected near-future changes. Journal of Geophysical Research 111, D19306. http://dx.doi.org/10.1029/2006JD007100.

Srivastava, S., Sheel, V., 2013. Study of tropospheric $\mathrm{CO}$ and $\mathrm{O}_{3}$ enhancement episode over Indonesia during Autumn 2006 using the Model for Ozone and Related chemical Tracers (MOZART-4). Atmospheric Environment 67, 53-62.

Streets, D.G., et al., 2003a. An inventory of gaseous and primary aerosol emissions in Asia in the year 2000. Journal of Geophysical Research 108 (D21), 8809. http:// dx.doi.org/10.1029/2002JD003093.
Streets, D.G., Yarber, K.F., Woo, J.H., Carmichael, G.R., 2003b. Biomass burning in Asia: annual and seasonal estimates and atmospheric emissions. Global Biogeochemical Cycles 17, 1099. http://dx.doi.org/10.1029/2003GB002040.

Tipayarom, D., Kim Oanh, N.T., 2007. Effects from open rice straw burning emission on air quality in the Bangkok metropolitan region. Journal of Science Asia 33 (3), 339-345.

Thompson, A.M., Witte, J.C., Hudson, R.D., Gao, H., Herman, J.R., Fujiwara, M., 2001. Tropical tropospheric ozone and biomass burning. Science 291, 2128-2132.

van der Werf, G.R., Randerson, J.T., Giglio, L., Collatz, G.J., Kasibhatla, P.S., Arellano Jr., A.F., 2006. Interannual variability in global biomass burning emissions from 1997 to 2004. Atmospheric Chemistry and Physics 6, 34233441. http://dx.doi.org/10.5194/acp-6-3423-2006.

Yurganov, L.N., McMillan, W.W., Dzhola, A.V., Grechko, E.I., Jones, N.B., van der Werf, G.R., 2008. Global AIRS and MOPITT CO measurements: validation, comparison, and links to biomass burning variations and carbon cycle. Journal of Geophysical Research 113, D09301. http://dx.doi.org/10.1029/ 2007JD009229.

Zhang, et al., 2011. Impacts of 2006 Indonesian fires and dynamics on tropical upper tropospheric carbon monoxide and ozone. Atmospheric Chemistry and Physics 11, 10929-10946. http://dx.doi.org/10.5194/acp-11-10929-2011. 